\title{
A COMPARISON BETWEEN SYNTHETIC AND BIOSYNTHETIC MESHES IN THE SURGICAL TREATMENT OF SEVERE GENITAL PROLAPSE: RESULTS AND COMPLICATIONS
}

\author{
S. Dati ${ }^{1}$, V. De Lellis ${ }^{2}$, P. Palermo ${ }^{2}$, G. Carta ${ }^{2}$ \\ 1 Urogynecology Unit, Policlinico Casilino, Rome \\ 2 Department of Obstetrics and Gynecology, University of L'Aquila
}

Keywords: Synthetic; biosynthetic meshes; pelvic organ prolapse.

\section{SUMMARY}

The effectiveness, tolerability and complications of two surgical procedures using prosthetic materials with different physical and structural properties were assessed with a full Urogynecology work-up, through a retrospective study of 158 patients with severe genital prolapse (POP-Q staging III-IV) selected from November 2006 to April 2009. Eighty-six patients underwent fascial replacement surgery with ProliftTM System with a dual transobturator access in the anterior district and a transperineal posterior access with a synthetic polypropylene type I mesh (Group A). Seventy-two patients who underwent pelvic organ prolapse surgery with Avaulta/Avaulta PlusTM System with a dual transobturator access in the anterior district and a dual transperineal posterior access with a biosynthetic polypropylene type I mesh coated with a film of hydrophilic porcine collagen were placed in Group B. There were no intra and postoperative complications. Results of mean 20.8 month follow-up showed an effective anatomical cure rate of $89.5 \%$ in group A and $86.1 \%$ in group B and a low percentage of erosive complications, $8.1 \%$ and $5.6 \%$ respectively. Validated questionnaires for prolapse, the UDI 6 s.f., the IIQ7 s.f. and the PISQ-12 all showed a statistically significant improvement of quality of life in patients undergoing the two procedures (Wilcoxon test: $\mathrm{P}<0.001$ ). 


\section{INTRODUCTION}

Although the introduction of synthetic materials for the surgical repair of pelvic organ prolapse (POP) has led to an excellent anatomical restoration and lower recurrence rates with a good functional outcome, the morbidity from erosion remains a challenge. Type I macroporous monofilament polypropylene meshes have proven to have good biocompatibility in vaginal tissues, but even so there are mesh-related complications that could have a significant impact on quality of life such as erosion, infection, rejection, dyspareunia, de-novo urinary or bowel symtoms. Clinical experience has shown that many risk factors may affect tissue acceptance of the mesh. The density of graft material and other physical characteristics like pore size, type and size of the mesh, patient's characteristics such as age and estrogen deficiency, method of fixation, type of surgery and concomitant procedures all play a significant role in mesh erosion.

The aim of this retrospective study is to compare the effectiveness, tolerability and complications of two surgical procedures, Prolift ${ }^{\mathrm{TM}}$ Total System vs Avaulta ${ }^{\text {TM }} /$ Avault Plus ${ }^{\text {TM }}$ Support System anterior/posterior, using prosthetic materials with different structural and physical properties to repair severe genital prolapse (stages III-IV POP-Q, ICS validated system).

The synthetic mesh ${ }^{1}$ used in the Prolift System is an extensive preshaped network with 4 anterior and 2 posterior arms of polypropylene monofilament macroporous type I, soft, knotted and nonabsorbable (Gynecare Gynemesh PS).

In the Avaulta Biosynthetic Support System ${ }^{2}$ the center body of the graft is made of Pelvitex, a soft, lowdensity, large-pored polypropylene that is coated with a film of hydrophilic porcine collagen (atelocollagen type I) which is absorbed in 21 days and may reduce the intensity of inflammatory response and possibly graft erosion. Both anterior and posterior meshes have four arms made of strongly knit polypropylene monofilament macroporous Type 1.

The more recent Avaulta Plus ${ }^{3}$ Biosynthetic Support System (Bard Urological) features a porous, acellular, ultra-thin sheet of crosslinked collagen attached to the polypropylene mesh which serves to establish a protective barrier between mucosal tissue and the polypropylene mesh and contains apertures uniformly sized to allow the ingrowth of host tissue and capillary vessels.

\section{MATERIALS AND METHODS}

A total of 158 women with recurrent or primary vaginal wall prolapse stage III or more (POP-Q system) scheluded to undergo surgery between November 2006 and April 2009 at the "Policlinico Casilino" Uro-gynaecology Unit in Rome and at the University of L'Aquila Department of Obstetrics and Gynecology were enrolled in this study. A detailed inform consent was obtained from each patient prior to surgery. Patients were 
divided into two groups according to the type of surgery: 82 patients undergoing fascial replacement surgery with synthetic mesh (Prolift) were included in Group A and 72 patients undergoing pelvic organ prolapse surgery with biosynthetic mesh were placed in Group B (39 of these latter patients underwent the Avaulta procedure and 33 the Avaulta Plus procedure).

The choice for the type of surgery was made in mutual agreement between physician and patient.

The average age of the study population was 63.4 years (range 41-78), the mean BMI 26.5 (range 19-42) and mean parity 2.3 (range $1-5$ ); moreover, $77.8 \%$ of the patients were menopausal with 44 receiving hormone replacement therapy.

Exclusion criteria included a previous hysterectomy and pelvic organ cancer regardless of the year of debut and treatment, previous anti-incontinence surgical therapy, insulin-dependent diabetes (type 1), severe rheumatic disease requiring peroral steroid treatment, systemic connective tissue disorder, physical or mental inability to participate in follow-up or give inform consent to participate in the study, overactive bladder symptoms associated with detrusor overactivity (OAB/DO).

Before surgery, all patients underwent a full urogynecological workup including: pelvic organ prolapse quantification (POP-Q) score, urine culture, micturition diary, $1 \mathrm{~h}$ pad test (ICS), Q-tip test, stress test before and after repositioning of the prolapse, visual analogic scale (VAS) for pro- lapse, Agachan-Wexner costipation scoring system, complete urodynamic investigation with uroflussometry, cystomanometry, Valsalva leak point pressure, pressure-flow study, pelvic ultrasound investigation including translabial 3D imaging with microconvex probes.

The following validated questionnaires were used to evaluate subjective outcomes: the Urogenital Distress Inventory (UDI-6), the Incontinence Impact Questionnaire s.f. (IIQ-7) and the Pelvic Organ Prolapse/Urinary Incontinence Sexual Questionnaire (PISQ-12).

According to the POP-Q staging system, prolapse was classified as stage III in 124 patients: 67 in group $A$ and 57 in group B. Nineteen patients in group A and 15 in group B had a stage IV prolapse. The mean subjective VAS for prolapse was 8.2 and 7.9 in the two groups respectively. Stypsis occurred in 94 patients (50 group A and 44 group B) with an Agachan-Wexner score always $<5$ (negative for obstructed defecation syndrome) (Tab. 1).

Among all the patients selected for the study 40 (25.3\%) showed clinical SUI (Stress Urinary Incontinence), 45 (28.5\%) latent SUI, and 73 (46.2\%) had no SUI. The urodinamic pressure/flow study (Pdet Max/ free Q max) showed a cervicourethral obstruction in 36 out of 86 patients in group $\mathrm{A}$ and in 29 out of 72 in group $\mathrm{B}$ (stage 2/3 according to the BlaivasGroutz nomogram). Mean total UDI-6 scores of 8.2 and 8.7 and IIQ-7 of 6.9 and 7,6 were found in group $\mathrm{A}$ and $\mathrm{B}$ respectively. Forty-two patients were 
Tab. 1 - Pre-operative workup

\begin{tabular}{|c|c|c|c|c|c|}
\hline & $\mathrm{Ba}$ & $\mathrm{C}$ & Bp & $\begin{array}{l}\text { Prolift } \\
\text { (86) }\end{array}$ & $\begin{array}{c}\text { Avaulta/A. Plus } \\
\text { (72) }\end{array}$ \\
\hline Stage $>$ III & $3.2 \pm 0.8$ & $2.7 \pm 0.8$ & $2.5 \pm 0.7$ & $77.9 \%$ & 79. $1 \%$ \\
\hline Stage IV & $4.6 \pm 1.3$ & $7.8 \pm 0.6$ & $3.8 \pm 0.4$ & $22.1 \%$ & $20.9 \%$ \\
\hline \multirow{3}{*}{ SUI } & & Clinical & $25.3 \%$ & 21 & 19 \\
\hline & & Latent & $28.5 \%$ & 25 & 20 \\
\hline & & No & $46.2 \%$ & 20 & 33 \\
\hline \multicolumn{4}{|c|}{ Stage 3 Blaivas/Groutz nomogram } & $40.7 \%$ & $40.3 \%$ \\
\hline \multicolumn{4}{|c|}{ VAS for prolapse (mean range) } & 8.2 & 7.9 \\
\hline \multicolumn{4}{|c|}{ OAB symptoms } & 62 & 52 \\
\hline \multicolumn{4}{|c|}{ UDI 6 s.f. (mean range) } & 8.2 & 8.7 \\
\hline \multicolumn{4}{|c|}{ IIQ s.f. (mean range) } & 6.9 & 7.6 \\
\hline \multicolumn{4}{|c|}{42 patients $\mathrm{PISQ}-12$ (mean range) } & 23.8 & 23.4 \\
\hline
\end{tabular}

sexually active (23 in group A and 19 in group B) and 23 of them (13 A e 10 B) suffered from preoperative dyspareunia with mean PISQ-12 scores of 23.8 (A) and 23.4 (B).

One hundred four patients (65.8\%) underwent a concomitant vaginal hysterectomy while 54 received a conservative treatment. A thirty day local estrogen treatment was given to all patients other than those receiving hormone replacement therapy.

All patients underwent an intravenous short-term intra and postoperative antibiotic prophylaxis with ceftazidime and metronidazole. Procedures were performed under epidural anesthesia in $67.1 \%$ of patients, spinal anesthesia in $17.1 \%$ and general anesthesia in $15.8 \%$.

All patients were available for clin- ical examination or phone update at 3-6-12-24 months.

\section{SURGICAL PROCEDURE}

\section{a) Anterior implant}

After antiseptic vaginal preparation an indwelling catheter is placed. If a decision of uterus preservation is made the first step of the operation is an incision of the anterior vaginal wall from the cervix to a point approximately $3-4 \mathrm{~cm}$ from the urinary meatus in order to protect and preserve the region of the bladder neck. If a vaginal hysterectomy is performed vesicovaginal retrodissection is carried out without longitudinal incision of the anterior vaginal wall. Wide lateral dissection enables identification of the tendinous arch of the 
pelvic fascia between the pubic symphysis and the ischial spine. Then the standard skin mapping for the passage of the needles and mesh arms is performed. The upper points are marked in the genitofemoral fold at the level of the urethral meatus and the lower points are located $2 \mathrm{~cm}$ below and $1 \mathrm{~cm}$ lateral from the upper ones. Then small skin incisions (4-5 $\mathrm{mm}$ ) are made.

Under permanent control by the fingers of the surgeon, the two upper needles are introduced through the superior-medial stab incisions and guided to perforate the obturator foramens in their antero-medial edges. The distal tips exit 1-2 cm laterally from the proximal end of the tendinous arches. The inferolateral transobturator needle passage is then made bilaterally in the outside-in direction to the paravaginal space behind the arcus tendinous of the pelvic fascia, $1 \mathrm{~cm}$ from the ischial spine.

In the Prolift procedure cannulaequipped guides are used. A retreival device is introduced into each cannula and graft deployment is accomplished using the retrieval loops to capture the distal end of the graft arms which are then pulled through the cannulas to the skin incisions. After the adjustment of the mesh the cannulas are sequentially removed and the the protruding graft arms are cut below skin level.

In the Avaulta procedure, graft placement is accomplished using a flexible snare system designed to allow for easy tip exteriorization and mesh arm capture.

\section{b) Posterior implant}

After hydrodissection and preparation of the rectovaginal space, the pararectal space is opened and the edges of the levator ani muscles can be seen. The dissection is continued until the ischial spines and the sacrospinous ligaments can be palpated first at one side and then at the other side. Small perineal skin incisions are made three $\mathrm{cm}$ lateral and three $\mathrm{cm}$ down from the anus on both sides. The needle is then advanced carefully, with the rectum retracted out of the way, through the buttocks and the fossa ischio-rectalis, controlled by the surgeon fingers, until it reaches the sacrospinous ligament approximately 2 to $3 \mathrm{~cm}$ medial to the ischial spine. Then it is pushed through the sacrospinous ligament under digital control. In the Prolift procedure only one introducer passage is required on each side. The tip of the guide and cannula is advanced out of the vaginal dissection, at which point the needle is removed while mantaining the cannula in position. After that the retreival device is passed down and advanced out of the cannula. Once the contralateral side is complete the mesh straps are introduced into the loops that are then pulled through the cannulas to the proximal edges.

In the Avaulta plus procedure, two introducer passages are required on each side because the posterior graft has four limbs; however, each side's arms exit through the same skin incision obviating the need for extra skin wounds. The proximal arms are placed first and the graft is positioned 
Tab. 2 - Anatomical outcome

\begin{tabular}{|c|c|c|c|c|c|}
\hline \multicolumn{4}{|c|}{ A) Annatomical End Point } & $\begin{array}{l}\text { Prolift } \\
\text { Group A }\end{array}$ & $\begin{array}{c}\text { Avaulta/A. Plus } \\
\text { Group B }\end{array}$ \\
\hline $\mathrm{Ba}$ & $\mathrm{C}$ & Bp & Wilcoxson test & \multirow{2}{*}{$\begin{array}{c}77 / 86 \\
(89.5 \%)\end{array}$} & \multirow{2}{*}{$\begin{array}{c}62 / 72 \\
(86.1 \%)\end{array}$} \\
\hline$-3.1 \pm 0.4$ & $-6.1 \pm 0.3$ & $-2.9 \pm 0.5$ & $\mathrm{P}<0.001$ & & \\
\hline \multicolumn{4}{|c|}{ Cystocele $<$ stage 2 symptomatic } & 3 & 3 \\
\hline \multicolumn{4}{|c|}{ Cystocele $\geq$ stage 2 symptomatic } & 2 & 2 \\
\hline \multicolumn{4}{|c|}{ Rectocele $\geq$ stage 2 symptomatic } & 1 & 1 \\
\hline \multicolumn{4}{|c|}{ Hysterocele $\geq$ stage 2 symptomatic } & 3 & 4 \\
\hline
\end{tabular}

by threading the proximal arms into the introducer eyelets, which are then withdrawn. After placing and tensioning of the central body, the distal arms are placed by passing the same needle through the same incision exiting into the vaginal incision at the level of the perineal body.

\section{TECHNICAL NOTES}

In order to reduce the risk of erosion, many preventive measures are taken in this study: antibiotic prophylaxis, change of surgical gloves after the primary dissection, no resection of the surplus of vaginal wall, no vaginal T-shaped incisions, meticulous attention to hemostasis, gentle handling of tissues, tension-free positioning of the mesh ${ }^{4-5-6}$. Furthurmore, the dissection of the anterior vaginal is performed so that the pubocervical fascia remaines attached to the vaginal wall?.

\section{RESULTS AND COMPLICATIONS}

Average operative time was $50^{\prime} \pm 10^{\prime}$

Tab. 3 - Functional Outcome

\begin{tabular}{|l|c|c|}
\hline & $\begin{array}{c}\text { PROLIFT } \\
\text { Group A (86) }\end{array}$ & $\begin{array}{c}\text { AVAULTA/A. PLUS } \\
\text { Group B (72) }\end{array}$ \\
\hline De novo dyspareunia & $2 / 10$ & $1 / 9$ \\
\hline Improved dyspareunia & $9 / 13$ & $7 / 10$ \\
\hline Improved stypsis & $37 / 50$ & $24 / 44$ \\
\hline De novo urge incontinence & 6 & 5 \\
\hline
\end{tabular}


Fig. 1 - Quality of life

\section{PROLIFT}

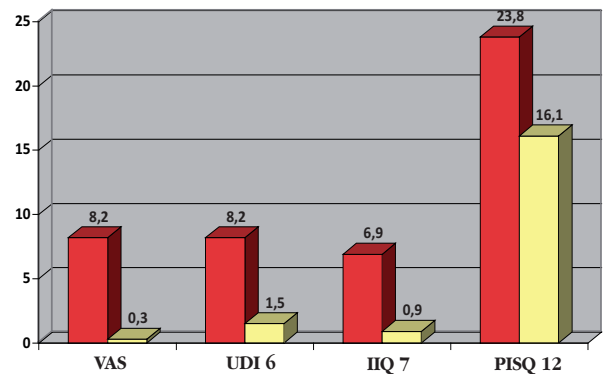

for isolated Prolift Total ${ }^{\mathrm{TM}}$ and Avaulta ant/post /Avaulta Plus ${ }^{\mathrm{TM}}$ procedures. Mean hospital stay was 3.5 days.

At a mean 20.8 month (3-33 months) follow-up there was a significant improvement in anatomical support in all vaginal wall compartments in both groups. The objective anatomical cure rate was $89.5 \%$ in group A and $86.1 \%$ in group B (Tab. 2).

The functional outcome with regard to dispareunia, stypsis and urge incontinence is summarized in Table 3. De novo dyspareunia occurred in 2 out of 10 patients in group $\mathrm{A}$ and 1 out of 9 in group B, while improvement in dyspareunia occurred in 9 out of 13 and 7 out of 10 in group A and $\mathrm{B}$ respectively.

Among the 50 patients complaining stypsis in the Prolift group and the 44 in the Avaulta group, a significant improvement occurred in 37 and 24 patients respectively.

The VAS questionnaires for prolapse, the UDI 6 s.f., the IIQ7 s.f. and the PISQ-12 all showed a statistically significant difference in the improvement of quality of life in patients un-
AVAULTA / AVAULTA PLUS

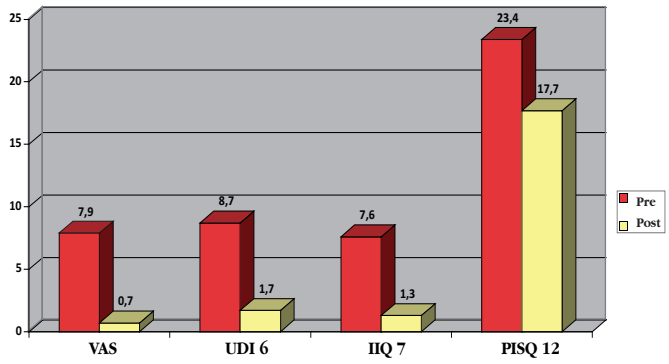

dergoing the two procedures (Wilcoxon test: $\mathrm{P}<0.001$ ) (Fig. 1).

No major intra and postoperative complications occurred such as bladder injuries or rectal perforation and there were no cases of bleeding in excess of $500 \mathrm{ml}$. Mesh exposure occurred in $8.1 \%$ of patients in group A and $5.6 \%$ in group B (Tab. 4).

\section{CONCLUSIONS}

The comparative study conducted on 158 patients with severe urogenital prolapse and undergoing surgical procedure Prolift SystemTM vs Avaulta / Avaulta Plus SystemTM showed that:

1. the lower density of the mesh and $\%$ of polypropylene ( 41 $\mathrm{gr} / \mathrm{mm}^{2}$ vs $36 \mathrm{gr} / \mathrm{mm}^{2}$ ) in the "coated" mesh doesn't affect anatomical outcome significantly;

2. the faster post-implant healing and the lower local morbidity that are associated with biosynthetic support systems both reduce the incidence of mesh erosion;

3. the reduced size of the pre-shaped 
Tab. 4 - Complications

\begin{tabular}{|c|c|c|c|c|}
\hline & & & $\begin{array}{l}\text { Prolift } \\
\text { Group A } \\
\text { (86) }\end{array}$ & $\begin{array}{c}\text { Avaulta/A.Plus } \\
\text { Group B } \\
\text { (72) }\end{array}$ \\
\hline \multirow[t]{3}{*}{ POST-OPERATIVE } & \multicolumn{2}{|c|}{$\begin{array}{l}\text { Perineal Abscess } \\
\text { Retropubic/pararectal }\end{array}$} & 0 & 0 \\
\hline & \multicolumn{2}{|c|}{ Pelvic Hematoma - Seroma } & 2 & 1 \\
\hline & \multicolumn{2}{|c|}{ Pelvic cellulitis } & 0 & 0 \\
\hline \multirow[t]{2}{*}{$\begin{array}{l}\text { SHORT-TERM } \\
\text { FOLLOW-UP }\end{array}$} & \multicolumn{2}{|c|}{$\begin{array}{l}\text { Vesicovaginal/rectovaginal } \\
\text { fistula }\end{array}$} & 0 & 0 \\
\hline & \multicolumn{2}{|c|}{ Partial exposure } & 8 & 6 \\
\hline \multirow[t]{5}{*}{$\begin{array}{l}\text { MID-TERM } \\
\text { FOLLOW-UP }\end{array}$} & \multicolumn{2}{|l|}{ Erosion } & $\begin{array}{c}7 \\
(8.1 \%)\end{array}$ & $\begin{array}{c}4 \\
(5.6 \%)\end{array}$ \\
\hline & \multicolumn{2}{|c|}{ Granulomas \pm exposure } & 6 & 5 \\
\hline & \multicolumn{2}{|c|}{ Mesh retraction } & 9 & 11 \\
\hline & \multirow{2}{*}{$\begin{array}{l}\text { Median } \\
\text { Synechiae } \\
\text { Vaginal } \\
\text { fundus }\end{array}$} & asymptomatic & 10 & 7 \\
\hline & & symptomatic & 1 & 1 \\
\hline
\end{tabular}

Avaulta mesh vs Prolift may favor collagen shrinkage and retraction of the mesh arms, as showed in our results;

4. the predominant anatomic site of erosion has been identified on the distal portion of the sagittal incision of the anterior colpotomy, highlighting therefore the protective effect of retrodissection without colpotomy.

In conclusion, although some questions about the use of different prosthetic materials in the repair of severe pelvic organ prolapse have not been resolved yet, our experience shows, in a midterm follow-up, that the macroporosity of the polypropylene type I, coated with a film of atelocollagen or protected with an ultrathin sheet of crosslinked collagen, improves graft tolerance favoring rapid growth of new connective tissue $^{8}$. We believe that the prevalence of mesh related complications may be reduced in many ways: taking proper protective measures, improving surgical skills and physical properties of prosthetics ${ }^{9}$ and last but not least acquiring a better knowledge of clinical manifestations to allow an appropriate management ${ }^{10}$. 


\section{References}

1. P. DEBODINANCE, M. COSSON, et al. :

Les prothèses synthétiques dans la cure de prolapsus génitaux par la voie vaginale: bilan en 2005.

J Gynecol Obstet Biol Reprod 2006; 35 (cahier 1): 429-454.

2. JAKUS S.M., SHAPIRO A., HALL C.D. :

Biologic and synthetic graft use in pelvic surgery: a review.

Obstet Gynecol Surv 2008 Apr; 63(4): 253-66.

3. DE TAYRAC R. et al. :

Prolapse repair by vaginal route using a new protected low-weight

polypropylene mesh: 1-year functional and anatomical outcome in a prospective multicentre study.

Int Urogynecol J (2007) 18: 251-256.

4. CAQUANT F., COLLINET P., DEBODINANCE P., BERROCAL J., GARBIN O., ROSENTHAL C., CLAVE H., VILLET R., JACQUETIN B., COSSON M. :

Safety of Trans Vaginal Mesh procedure: retrospective study of 684 patients.

J Obstet Gynaecol Res 2008 Aug; 34(4): 449-56.

5. FATTON B., AMBLARD J., DEBODINANCE P., COSSON M., JACQUETIN B. : Transvaginal repair of genital prolapse: preliminary results of a new tensionfree vaginal mesh (Prolift ${ }^{T M}$ Technique) A case series multicentric study. Int Urogynecol J (2007) 18: 743-752.

6. FALAGAS M.E., VELAKOULIS S., IAVAZZO C., ATHANASIOUS S. : Mesh-related infections after pelvic organ prolapse repair surgery.

Eur J Obstet Gynecol Reprod Biol 2007 Oct;134(2):147-56. Epub 2007 Apr 24.

7. LE T.H., KON L., BATHIA N.N., OSTERGARD D.R. :

Update on the utilization of grafts in pelvic reconstruction surgeries.

Curr Opin Obstet Gynecol 2007 19: 480-489.

8. RABA G., CHAMULA W. :

Management of selected complications following urogynecological surgeries with the use of synthetic prostheses-own observations.

Ginekol Pol 2008 Aug; 79(8): 550-4.

9. BELOT P., COLLINET P., DEBODINANCE E., HA DUC, J.-P. LUCOT, M. COSSON :

Facteurs de risque des expositions prothétiques après cure de prolapsus génital par voie vaginale Risk factors for prosthesis exposure in treatment of genital prolapse via the vaginal approach.

Gynécologie Obstétrique \& Fertilité 33 (2005) 970-974.

10. KOBASHI K. :

Management of erosion of graft materials in pelvic floor reconstruction.

Scientific Word Journal 2009 Jan 18; 9: 32-6. 